IFN Working Paper No. 884, 2011

\title{
The Intergenerational Transmission of Cognitive and Non-Cognitive Abilities
}

Erik Grönqvist, Björn Öckert and Jonas Vlachos 


\title{
The intergenerational transmission of cognitive and non-cognitive abilities $^{a}$
}

\author{
by \\ Erik Grönqvist ${ }^{\mathrm{b}}$, Björn Öckert ${ }^{\mathrm{c}}$ and Jonas Vlachos ${ }^{\mathrm{d}}$
}

2011-07-05

\begin{abstract}
We study the intergenerational transmission of cognitive and non-cognitive abilities between fathers and sons using population-wide enlistment data. Measurement error bias in fathers' ability measures is corrected for using two sets of instruments. Results suggest that previous estimates of intergenerational ability correlations are biased downwards; once corrected for, the non-cognitive correlation is close to that of cognitive ability. We also predict mothers' abilities and find the mother-son cognitive ability correlation to be stronger than the father-son correlation. Finally, educational attainment and labor market outcomes of both sons and daughters are strongly related to both parents' cognitive and non-cognitive abilities.
\end{abstract}

Keywords: Intergenerational ability correlations, cognitive ability, non-cognitive ability, measurement error bias

JEL-codes: I0, J13, J24

\footnotetext{
${ }^{a}$ We have benefitted from comments and suggestions from Mikael Lindahl, Matthew Lindquist, Erik Lindqvist, Petter Lundborg, Per Pettersson-Lidbom, Erik Plug, Analia Schlosser, Peter Skogman-Thoursie and seminar participants at the EEEPE conference in London 2009, the EALE-SOLE 2010 meetings in London, UCLS workshop in Öregrund 2010, ELE workshop in Sitges 2010, the National Conference of Swedish Economists in Lund 2010, the Institute for Labour Market Policy Evaluation (IFAU), the Research Institute for Industrial Economics (IFN), Zentrum für Europäische Wirtschaftsforschung (ZEW), CAFO Linnaeus University, Lund University, Aarhus University and Tel Aviv University. Jonas Vlachos gratefully acknowledges financial support from the Marianne and Marcus Wallenberg Foundation.

${ }^{\mathrm{b}}$ Institute for Labour Market Policy Evaluation (IFAU) and Department of Economics, Uppsala University. Email: erik.gronqvist@ifau.uu.se

${ }^{c}$ Institute for Labour Market Policy Evaluation (IFAU) and Department of Economics, Uppsala University. Email: bjorn.ockert@ifau.uu.se

${ }^{\mathrm{d}}$ Department of Economics, Stockholm University, IFN and CEPR. Email: jonas.vlachos@ne.su.se
} 



\section{Introduction}

A large literature recognizes the importance of not only cognitive abilities but also of noncognitive abilities - or personality traits - for labor market outcomes (e.g. Bowles, 2001; Heckman et al., 2006; Lindqvist and Vestman, 2011). Despite the growing mass of research on non-cognitive abilities (Borghans et al., 2008), the role of parents in shaping such personality traits is still far from fully understood. A better insight of this is vital to enhance our understanding of how economic outcomes are transmitted over generations. One fundamental problem when studying the relation between parental abilities and the abilities of their offspring is that abilities are likely to be measured with error. As is well known, random measurement errors will induce attenuation bias that lead to an under-appreciation of the influence that parents have on their children (Black and Devereux, 2010). This may be particularly problematic when comparing the intergenerational transmission of cognitive and non-cognitive skills as the measurement problems are likely to be more severe for noncognitive traits. Measurement error can therefore lead to unfounded beliefs that parental influences are less important for non-cognitive than for cognitive abilities.

In this paper we make use of military enlistment records for 37 cohorts of Swedish men, where fathers' and sons' abilities are evaluated at the same age (approximately 18) and where the evaluation methods are comparable over time. This enables us to estimate intergenerational correlations in both cognitive and non-cognitive abilities using the same sample of individuals. We correct for measurement error in fathers' abilities using two different sets of instrumental variables: For a smaller sample $(n \approx 2000)$, we use comparable ability evaluations for fathers at age 13 . For a much larger sample ( $\approx \approx 50000$ ), ability evaluations of the son's uncle (i.e., the father's brother) are employed as instruments for the 
father's abilities, thus utilizing the sibling correlation. ${ }^{5}$ The two instruments provide very similar results. The exclusion restriction that uncles do not have a direct effect on the skills of their nephews is also supported by a series of validity checks. In addition, the second IV strategy enables us to predict mothers' abilities by using the ability evaluations of their brothers, thus bringing both parents into the analysis.

Without adjusting for measurement error, we find a father-son correlation of $0.32-0.35$ for cognitive and 0.21 for non-cognitive abilities, much in line with previous findings: Black et al. (2009) and Björklund et al. (2010) find intergenerational correlations in cognitive abilities of between 0.35 and 0.38 , while the meta-study by Plomin and Spinath (2004) reports a correlation of 0.4. As for non-cognitive abilities, the meta-study by Loehlin (2005) reports an intergenerational coefficient of about 0.15, while Dohmen et al (2008) find coefficients between 0.15 and 0.25 . Anger (2010) finds correlations ranging from 0.12 to 0.22 between parents and their young adult children. ${ }^{6}$ When we adjust for measurement error in fathers' abilities, the intergenerational correlation increases to $0.42-0.48$ for cognitive, and to around 0.42 for non-cognitive abilities. ${ }^{7}$ This suggests that the substantial difference in estimated intergenerational correlations between cognitive and non-cognitive abilities found in the previous literature, to a large extent is due to a higher degree of measurement error in noncognitive abilities. This is unlikely to be a unique feature of our data.

We next derive predicted cognitive and non-cognitive ability measures also for mothers using the enlistment evaluations of their brothers; i.e. the maternal uncles. The results show that mother-son correlations in cognitive abilities are somewhat stronger than father-son

\footnotetext{
${ }^{5}$ The brother correlation in cognitive and non-cognitive abilities in our data is 0.45 and 0.30 respectively, thus ensuring a strong first stage.

${ }^{6}$ These studies all use different measures of non-cognitive abilities and personality traits. For example, Dohmen et al. (2008) study risk taking and trust attitudes while the results in Loehlin (2005) and Anger (2010) are related to the 'big five' personality traits: openness, conscientiousness, extraversion, agreeableness, and neuroticism. Anger also studies the internal and external locus of control. A related paper by Wilhelm et al (2008) reports that intergenerational correlations in attitudes for charitable giving ranges from 0.26 to 0.31 for religious giving and 0.08 to 0.14 for secular giving.

${ }^{7}$ Note that Bowles and Gintis (2002) argue that the intergenerational correlation in cognitive ability lies between 0.42 and 0.72 when taking measurement error into consideration.
} 
correlations, while no such difference is apparent for non-cognitive abilities. Previous studies on the relative ability correlations between mothers and fathers have produced inconclusive results, perhaps due to quite small sample sizes yielding imprecise estimates. ${ }^{8}$ With the large sample at our disposal, the correlations we report are estimated with a high degree of precision. Since both generations are evaluated at approximately age 18, another advantage of our data is that parental abilities are not influenced by experiences shared by parents and children, a consideration shown to be important in a recent contribution by Brown et al. (2011).

Finally, we find a strong association between (predicted) parental abilities - both fathers' and mothers' - and educational and labor market outcomes for both sons and daughters. Parents' cognitive abilities are relatively more important for educational outcomes while their non-cognitive abilities are relatively more important for earnings and labor force participation. Previous findings on the labor market effects of cognitive and non-cognitive abilities for men (Lindqvist and Vestman, 2011) are thus likely to apply to women as well. ${ }^{9}$ These results provide support for recent findings suggesting that the transmission of noncognitive skills can explain a substantial part of the intergenerational correlation in economic outcomes. For example, in a small sample of US children Osborne-Groves (2005) finds that personality traits can explain 11 percent of the earnings transmission, the same number as Blanden et al. (2007) find in a study of 3300 UK children using a measure of non-cognitive skills. Hirvonen (2009) finds that a combination of sons' education, cognitive and noncognitive skills, as well as a health indicator (BMI) can account for most of the

\footnotetext{
${ }^{8}$ Using representative but relatively small samples, Anger and Heineck (2009) and Anger (2010) report mother-son, motherdaughter, father-son, and father-daughter correlations for a number of cognitive and non-cognitive ability dimensions.

${ }^{9}$ Lindqvist and Vestman (2011) use the same type of enlistment data as we do. They find that a one standard deviation increase in the cognitive and non-cognitive skills measure is associated with 6 and 9 percent higher wages, respectively. Further, non-cognitive skills are strongly related to future labor force participation and the probability of living in poverty.
} 
intergenerational correlation in income. In the same vein, Björklund et al. (2010) find that indicators of parental patience can explain a substantial part of sibling income correlations.

The rest of the paper is organized as follows. Section 2 outlines the methodological considerations and section 3 presents the data. In section 4, we estimate father-son correlations with and without measurement error correction and present evidence concerning the validity of the uncle instrument. Section 5 derives ability measures for both parents and estimates intergenerational ability correlations using these. In section 6 , we estimate the relationship between parental abilities and educational attainment and labor market outcomes of both sons and daughters. Section 7 concludes.

\section{Methodological considerations}

With the aim of this paper, to estimate the correlation of cognitive and non-cognitive abilities between generations, we, ideally, would like to estimate the following simple regression model:

$$
Y_{j}^{* \text { son }}=\alpha+\beta Y_{j}^{* \text { father }}+\varepsilon_{j}
$$

where $Y_{j}^{* s o n}$ represents the true cognitive or non-cognitive ability for the son in family $j$, $Y_{j}^{*}$ father is the corresponding true ability for the father and $\varepsilon_{j}$ is an error term. The parameter $\beta$ is the intergenerational correlation in true cognitive or non-cognitive abilities between fathers and sons. ${ }^{10}$

A problem for this study - and essentially all other studies on the subject - is that the observed cognitive and non-cognitive ability evaluations will typically measure the true underlying abilities with errors. There are two potential sources of measurement errors in the

\footnotetext{
${ }^{10}$ All ability measures are standardized, why the slope coefficient equals the correlation coefficient.
} 
observed abilities, both of which may bias the estimates of the intergenerational correlations towards zero. First, the evaluation instrument can only test for a subset of the traits characterizing the underlying ability, and individuals may have good or bad realizations with respect to the specific items included in the test. Hence, the test may not fully capture the underlying ability it aims to measure. Second, some individuals perform particularly well or bad in the test taking situation.

To illustrate how the two types of measurement errors may affect our estimates, assume that the observed ability for individual $i$ in family $j, Y_{j}^{i}$, can be expressed as linear function of the true latent ability, $Y_{j}^{*_{i}}$, a test specific measurement error, $\lambda_{j}^{i}$, and an individual specific measurement error, $\eta_{j}^{i}$ :

$$
Y_{j}^{i}=Y_{j}^{* i}+\lambda_{j}^{i}+\eta_{j}^{i}
$$

Under the assumption that both types of measurement errors are classical, i.e. independent random variables, the OLS estimate of the intergenerational correlation in true abilities can be expressed as:

$$
p \lim \beta^{\text {OLS }}=\beta \frac{V\left(Y_{j}^{* \text { father }}\right)}{V\left(Y_{j}^{\text {father }}\right)} .
$$

This is the usual measurement error bias expression, where the estimate of the intergenerational correlation is attenuated by the ratio between the variance of fathers' true and the observed abilities; i.e. the reliability ratio.

Noisy measures of the true latent ability of fathers is particularly problematic for our purposes, since the extent of measurement error may differ between the cognitive and noncognitive ability measures. In particular, we suspect the measurement error problem to be more severe for measures of non-cognitive skills than of cognitive skills, as the methods for testing cognitive abilities are more developed. The downward bias of the OLS estimates of intergenerational correlations in non-cognitive skills may thus be greater than that of 
cognitive skills, leading us to draw incorrect conclusions of the relative importance of the intergenerational transmission of different types of skills.

One way of dealing with measurement errors is to find an instrument for the noisy variable; that is, to find a variable that is strongly related to the fathers' abilities but without any direct effect on the sons' abilities (see e.g. Ashenfelter and Krueger, 1994). We propose two different sets of instruments to correct for measurement error bias in the estimated intergenerational correlations: First, we use a set of evaluations of the fathers' abilities conducted at an earlier age. Second, we use the ability evaluations of paternal uncles at the draft to instrument for fathers' abilities. This amounts to estimating the following first stage relation:

$$
Y_{j}^{\text {father }}=\pi+\rho Y_{j}^{i}+u_{j} \quad \text { for } i=\text { early age, uncle, }
$$

where $\rho$ is the correlation between the different ability evaluations. In the first case, we thus exploit the strong intrapersonal correlation between ability evaluations conducted at different ages to address the measurement error problem. In the second case, we exploit the strong correlation between siblings' abilities. Under the exclusion restriction that there is no direct effect from the father's ability at age 13 or the uncle's ability at age 18 on the son's abilities other than through their effects on the father's ability at age 18 - we are able to correct for the measurement error bias, and thus capture the intergenerational correlation in the true latent abilities:

$$
\operatorname{plim} \hat{\beta}_{I V}=\frac{\operatorname{cov}\left(Y_{j}^{\text {son }}, Y_{j}^{i}\right)}{\operatorname{cov}\left(Y_{j}^{\text {father }}, Y_{j}^{i}\right)}=\beta \frac{\operatorname{cov}\left(Y_{j}^{*} \text { father }, Y_{j}^{*} \text { father }\right)}{\operatorname{cov}\left(Y_{j}^{*} \text { father }, Y_{j}^{*} \text { father }\right)}=\beta \quad \text { for } i=\text { early age, uncle. }
$$

The exclusion restriction is quite innocent when considering the fathers' own ability evaluations conducted at an earlier age. The validity of the uncle instrument is more questionable as uncles can have a direct influence on their nephews, or they could share some family factor with their nephews not shared by the father. In such a case, the IV-estimate 
would overestimate the true transmission in abilities. Another possibility is that the measurement error may not be classic and, in particular, the brothers' measurement errors could potentially be correlated. If this is the case, the IV-estimate is likely to underestimate the intergenerational correlation in true skills. In Section 4.2 we will address these and related concerns about the validity of the uncle instrument. ${ }^{11}$

A second major concern is whether the local average treatment effect (Imbens and Angrist, 1994) identified using these IV-estimators capture the same parameter as the OLSestimators. In principle, it is possible that the intergenerational transmission of the abilities that are stable between the fathers' early and late evaluations, or that are shared between fathers and their brothers, may differ from the intergenerational transmission of fathers total abilities. Thus, any difference between the OLS and the IV estimates may not only be driven by measurement error, but also because the estimators exploit different parts of the variation in fathers' abilities. Since we have two different sets of instruments, both exploiting different sources of variation, our approach to address this issue is to compare the different IVestimates. In Appendix B, we present a simple structural production model of abilities which suggests that if the estimates using the different instruments are similar, it is highly likely that they capture the same parameter as the OLS-estimator.

\section{Data}

Up until 2010, all Swedish men were by law obliged to go through the military enlistment, if called upon. ${ }^{12}$ In most cases, the enlistment took place the year men turned 18. Up until the late 1990s, over 90 percent of all men in each cohort went through the whole enlistment

\footnotetext{
${ }^{11}$ In the event that the test specific measurement error is correlated over generations, both the OLS and the IV estimate will be biased upwards. We believe this is less of a problem, since the parental generation use a different version of the test than the sons' generation.

${ }^{12}$ The discussion of the enlistment data draws heavily on an interview with Johan Lothigius, chief psychologist at the National Service Administration, carried out by Erik Lindqvist (August 25, 2004). We are grateful to Erik for sharing his notes with us. See also Lindqvist and Vestman (2011) for additional details of the enlistment procedure.
} 
procedure; only the physically and mentally handicapped were exempted. ${ }^{13}$ Thereafter, the need for conscripts declined and the enlistment became less comprehensive.

The enlistment consists of a series of physical, psychological and intellectual tests and evaluations. The evaluation of cognitive ability consists of several subtests of logical, verbal, and spatial abilities, as well as a test of the conscript's technical comprehension. The design of the test has been subjected to minor revisions in 1980, 1994 and 2000, but throughout the period it tests for the same four underlying abilities. The raw test results on these four subtests are combined to a discrete variable of general cognitive ability ranging from 1 to 9 , which has been found to be a good measure of general intelligence (Carlstedt, 2000). We standardize this composite measure of general cognitive ability by enlistment year.

Our measure of non-cognitive abilities is based on a standardized psychological evaluation aimed at determining the conscripts' capacity to fulfill the requirements of military duty and armed combat. Central to this are the abilities to cope with stress and to contribute to group cohesion. A conscript is given a high score if considered to be emotionally stable, persistent, socially outgoing, willing to assume responsibility, and able to take initiatives. Motivation for doing the military service is, however, explicitly not a factor to be evaluated. The evaluation is performed by a certified psychologist who conducts a structured interview with the conscript. As a basis for the interview, the psychologist has information about the conscript's results on the tests of cognitive ability, physical endurance, muscular strength, as well as grades from school and the answers froma questionnaire on friends, family, hobbies etc. The interview follows a specific, and secret, manual that states topics to discuss and also how to grade different answers. Grades are given on four different sub-scales which are transformed to a discrete variable of non-cognitive ability ranging from 1 to 9 . Also this measure is

\footnotetext{
${ }^{13}$ The consequences of refusing the enlistment include fines and being round up by the police, and ultimately imprisonment in up to one year (1994:1809 Lag om totalförsvarsplikt, kap 10).
} 
standardized by enlistment year. The correlation between cognitive and non-cognitive abilities across individuals is 0.35 .

Data on enlistment files have been collected from administrative records kept by the Military Archives of Sweden and the National Service Administration. The original sample consists of all Swedish men born between 1950 and 1987, and includes information on date of the enlistment, results on the cognitive ability tests and the psychologist's rating of the noncognitive skills. Information from Statistics Sweden on biological parents has then been used to link fathers and sons, as well as mothers and siblings. ${ }^{14}$

A few restrictions on data have been imposed in the main analysis. All men included in our sample must have a valid enlistment record and have enlisted the year they turned 18, 19 or 20 years of age. Since over 90 percent of all men were enlisted up to the late 1990's, representativeness is a minor concern for most of the period studied. During the early 2000's, however, the share of men who were called to the enlistment fell dramatically. For individuals born in the mid 1980s, only 70 percent were enlisted. Thus, for individuals born towards the end of our sampling window, the selective enlistment might potentially pose a problem. We will return to this issue in section 4.5.

In order to correct for measurement error in the fathers' abilities we use two different strategies, both strategies impose separate sample restrictions. For a sample of fathers we have alternative measures of cognitive and non-cognitive abilities at age 13. These data originates from the longitudinal study Evaluation Through Follow-up (ETF) consisting of a 10 percent sample of individuals born in 1953. Within the ETF surveys, individuals were given cognitive ability tests reflecting some of the very same abilities as measured during the enlistment. Even though the cognitive tests at age 13 and 18 are not identical, they are supposed to reflect the

\footnotetext{
${ }^{14}$ In principle all individuals born in Sweden since 1932 can be linked to their mother and father. The qualification is that they are residents in Sweden in 1961 and later. For immigrants the coverage is much lower, but as only Swedish citizens were allowed (and obliged) to attend the enlistment this is a minor concern
} 
same underlying cognitive abilities. While the ETF data does not include any direct measurement of non-cognitive abilities, it does contain information capturing such personality traits. More specifically the ETF data contains information on father's grade point average (GPA) in non-theoretical subjects in the $6^{\text {th }}$ grade and survey information on educational aspirations and social interaction. ${ }^{15}$ We use the residual of these measures after regressing them on the ETF-measure of cognitive ability - thus netting out any cognitive ability — as instruments of the father's non-cognitive ability at age 18 .

Our second strategy is to use uncles' abilities as instruments for the father's abilities and we therefore restrict the sample to sons with at least one uncle. In addition, by requiring that both the father and the uncle have enlisted before 1980 we guarantee that they have undertaken the same version of the cognitive ability test. Further, to avoid that uncles share more of the same environment with their nephews than with their brothers, we require the age difference between fathers and uncles to be at most seven years. ${ }^{16}$

Subject to these restrictions, our main regression samples consists of almost 2000 observations (sons) for the ETF-sample and more than 50000 observations (sons) for the uncle sample. Table 1 shows descriptive statistics for sons, fathers and paternal uncles in our respective samples. As noted above, men are typically enlisted when they are 18 years old. There is some evidence that the sons in our sample have slightly higher cognitive and noncognitive skills than the population on average, while their fathers have slightly lower cognitive and slightly higher non-cognitive skills than their sons. ${ }^{17}$ This pattern is likely to be caused by the age restrictions in the enlistment data (individuals born 1950 to 1987) which

\footnotetext{
${ }^{15}$ The survey question on educational aspirations contain information on the number of years the student plans to study, while the question on social interaction captures the extent to which the student spend time outside school alone or with friends.

${ }^{16}$ As will be discussed later, we will also predict abilities for both parents using the enlistment evaluations of both paternal and maternal uncles. The restrictions on this sample will be slightly different as we require the relevant data to be available for both parents.

17 The residualized measures of the father's non-cognitive abilities at age 13 have been standardized, and, thus, are uninformative about how the father's non-cognitive abilities differs from the population as a whole.
} 
implies that the fathers in our sample are somewhat younger than fathers in the population as a whole. Paternal uncles are slightly younger than the fathers, since there is no requirement that uncles need to have children. They also have somewhat lower cognitive scores than fathers, possibly due to birth order effects with the uncle's in our sample typically being the younger brothers (Black et al., 2007).

\section{[Table 1]}

\section{$4 \quad$ Father-son correlations}

We start this section by presenting the results for intergenerational correlations in cognitive and non-cognitive abilities between fathers and sons with and without correction for measurement error. The main result, for both IV-strategies, is that correcting for measurement error leads to substantially higher intergenerational correlations in both cognitive and noncognitive abilities. The attenuation bias is particularly severe for non-cognitive abilities and once corrected for, the intergenerational correlation in personality traits is close to that of cognitive abilities. In Section 4.2, we present a number of consistency checks validating the use of the uncle instrument and in section 4.3 we present results from additional robustness checks on the validity of the draft measures and sample selection.

\subsection{Correlations with and without correcting for measurement error}

In this section, we estimate baseline intergenerational correlations in abilities - as measured at the military draft—with and without corrections for measurement error. In the first column in the top panel of Table 2, we see that the OLS-estimate of the relation between fathers' and sons' cognitive abilities is 0.32 for the ETF-sample. ${ }^{18}$ For the uncle-sample, the same estimate, in column 3, is 0.35 which is close to what Black et al. (2009) have found for

\footnotetext{
${ }^{18}$ As described in the previous section, the ETF-sample is the sample of fathers for which we have alternative ability evaluations conducted at age 13 .
} 
Norway and Björklund et al. (2009) for Sweden. In the first column in the lower panel, we instrument for fathers' cognitive abilities using the cognitive ability evaluation conducted at age 13 . The point estimate increases to 0.42 , implying a reliability ratio of 0.76 . In the third column, we instead instrument for fathers' cognitive abilities using the enlistment evaluation of their brothers, i.e. the uncle instrument. The IV-estimate is 0.48 which in turn implies a reliability ratio of 0.73 . This ratio is not statistically different from the reliability ratio in column one.

We next look at the intergenerational ability correlations for non-cognitive abilities. In columns two and four in the top panel, we see that the OLS-estimates are 0.21 both for the ETF- and the uncle-sample, which is in line with previous findings. ${ }^{19}$ In the second column in the lower panel, we correct the estimates for attenuation bias by using the fathers' noncognitive ability evaluations at age 13 as instruments. The point estimate then increases to 0.41 which means that the reliability ratio equals 0.51 . In the final column, we use the uncle instrument to correct for measurement error and get a point estimate of 0.42 , very close to the estimate in column two. The reliability ratio for the uncle instrument equals 0.5 which, again, is not statistically different from the reliability ratio we get using the age 13-instruments for non-cognitive abilities.

[Table 2]

Apart from the substantial increases in the intergenerational correlations when correcting for measurement error, the most striking finding in Table 2 is the similarity between the estimates based on the two different instruments for fathers' abilities. Recall that the ETFinstruments are based on evaluations of the fathers' own abilities at age 13 while the uncle instruments consist of the ability evaluations of the fathers' brothers. That both sets of

\footnotetext{
${ }^{19}$ The meta-study by Loehlin (2005) finds the intergenerational coefficient for non-cognitive abilities to be around 0.14. Dohmen et al. (2008) find the coefficient for risk taking and trust attitudes to be between 0.15 and 0.25.
} 
instruments yield consistent results is a strong indication that the exclusion restrictions holds but we will analyze this issue more closely in the next section.

The similarity between the estimates using different instruments also suggests that he IVestimates capture the same underlying relationship as the OLS-estimates. The instruments based on abilities evaluated at age 13 exploits all the variation in father's abilities as determined by genes, as well as all environmental determinants up to the age 13 . It does however not exploit the variation in the environmental determinants of father's ability between the age 14 and 18. If the environmental factors during this age period have limited impact on the father's abilities at age 18, the early ability instrument will in essence exploit all the determinants for the father's ability at age 18 and the instrument will capture the same parameter as do OLS. Since the uncle instrument and the early ability instrument produce very similar estimates, this suggests that the uncle instrument must also capture the same parameter as the OLS. On the contrary, if environmental factors between age 14 and 18 does have a substantial impact on fathers' abilities, the similarity between the different IVestimates suggests that the intergenerational transmission of genetic and environmental factors are similar. As discussed in a simple, and admittedly restrictive, ability production function presented in Appendix B, this again implies that the OLS and the IV capture the same underlying relationship.

One additional concern is that the high father-son correlation in non-cognitive ability may be spuriously driven by cognitive ability, as the cognitive ability is omitted in the regressions in columns two and four. Similarly, the estimates in columns one and three might be upwardly biased due to the omission of non-cognitive abilities. In Table 3, however, we find that the point estimates are only slightly reduced - to 0.44 for cognitive abilities and to 0.39 for noncognitive abilities - when controlling for the other ability type with the relative size being 
unchanged. Furthermore, these point estimates are not statistically different from the corresponding estimates in Table 2.

[Table 3]

To sum up, the results in this section show that OLS-estimates of intergenerational ability correlations are substantially downward biased, in particular for non-cognitive abilities. The larger measurement error in non-cognitive than in cognitive ability evaluations is not surprising as the concept of cognitive ability is more precisely defined and measurement methods more developed. That a substantial part of the differences in intergenerational correlations between cognitive and non-cognitive abilities can be explained by a higher degree of measurement error in the non-cognitive ability dimension is thus unlikely to be a unique feature of this study. Rather, the results suggest that previous estimates of intergenerational correlations in non-cognitive abilities have been quite severely downwardly biased due to measurement error.

The similarity in results between the two IV-strategies makes us confident in confining the remaining analysis on the uncle instrument, rather than using the much smaller sample we get when using the instrument from age 13. Before bringing mothers in to the analysis in section 5, we in section 4.2 and 4.3 provide additional support for the validity of the uncle instrument as well as performing additional robustness tests

\subsection{Can we trust the uncle instrument?}

Even if the similarity between the estimates using two different sets of instruments reported in the previous section indicates that the uncle instrument is valid, we in this section perform some additional tests of whether or not the exclusion restriction holds. This is crucial since a direct impact by uncles on their nephews' abilities - either by a direct influence, through shared environment, or shared genetic factors - would render the results based on the uncle instrument to be invalid. While the exogeniety of the instrument is an assumption that by 
definition cannot be tested, we in this section perform several consistency checks corroborating the exogeniety of the uncle instrument.

In order to avoid the son and his uncle to be sharing the same environment, we have as a precaution restricted the sample to uncles who are at most 7 years younger than the father. Table 1 shows that the average uncle is more than 25 years older than his nephew, reducing much of the shared time- and age-specific environmental influences. Despite this age difference, uncles could still have a direct influence on their nephews. We test for this by using a sub-sample of "absent uncles", defined as uncles who have either died or emigrated from Sweden prior to the birth of their nephew. The reasoning is as follows: If uncles have a direct effect on their nephews, IV estimates based on the ability evaluation for absent uncles — who have had no or very limited contact with their nephews — should be lower than for the average uncle.

Despite the drastic reduction in sample size, column two in Table 4 first shows that the OLS estimates for cognitive and non-cognitive skills are essentially unchanged compared to the estimates based on the full sample (estimates from Table 2 are displayed in column one to make comparisons easier). More importantly, the IV estimates for the absent uncle sample are, if anything, larger than the IV estimates based on the full sample of observations, and the reliability ratios are lower. It should be noted, however, that the standard errors of these IV estimates are large and we cannot reject the possibility that the IV estimates for the different samples are equal. Still, we find no evidence suggesting that the IV estimates for absent uncles are smaller, or that the reliability ratios are larger, compared to the estimates based on the full sample. This indicates that uncles do not have a direct influence on their nephew's abilities.

[Table 4] 
Even if uncles do not influence their nephews directly, they do have a shared environment through the grandparents. Grandparents may have an influence on both their sons and their grandsons, for example by spending time with their grandchildren. Hence, there may be an association between the uncle and his nephew, not shared with the father, potentially biasing the IV estimates of the father-son correlation upwards. In order to test for this we utilize subsamples of children with "absent grandparents", where the direct contact with the grandparents is broken. If there is an association between children and their uncles-not shared by the father-via the grandparents, the IV estimates based on a sample of sons with absent grandparents should be lower relative to the OLS estimates than for the full sample.

We first use a sample of children where either the grandmother or the grandfather died before their grandson was born. In column three in Table 4, we find the IV estimates for cognitive and non-cognitive skills to be essentially unchanged compared with the original estimates. In column four we instead use the small sample where both the grandmother and the grandfather died before their grandson was born. For this sample, the IV estimate for cognitive ability is slightly smaller, while the estimate for non-cognitive ability is larger, than for the full sample, but these differences are not statistically significant. It is important to note that the OLS estimates also differ somewhat from the estimates based on the full sample, most likely due to this sample being a highly selected one. It is therefore useful to study the reliability ratios rather than the IV estimates. If the original IV estimates were upward biased due to a direct influence by grandparents on their grandchildren, we would expect the reliability ratios for the absent grandparents sample to be higher than for the full sample. As for the absent uncle sample, we find no indication of this. This means that we find no sign of an independent association between the uncle and the nephew through the influence from the grandparents. 
So far we have considered the case where the uncle instrument could be invalid through either a direct influence from the uncle or through a shared environment. A third possibility is that there is a genetic component shared by the uncle and the nephew, but not by the father. In order to test for this possibility we consider a trait that has a large genetic component and for which measurement error is limited; namely stature. In the absence of such a genetic component only shared between uncles and nephews, we expect the OLS and IV estimates to be close to identical. Indeed, in Table 5 we find the OLS estimate of the father-son correlation in height to be 0.48 , whereas the IV estimate is 0.50 . As measurement error is not completely absent even for our measure of height, this slight difference can be explained by attenuation bias. ${ }^{20}$ Alternatively, it can be due to a small direct influence of the uncle on his nephew's stature. Either way, we feel reassured that any direct effect from the uncle through a shared genetic component is at most marginal.

[Table 5]

Through all the consistency tests performed we find no indication of a direct effect from the uncle to his nephew, either through a direct influence, a shared environment or through a common genetic component not shared by the father.

\subsection{Motivational factors and selection issues}

An issue concerning the measurement of abilities is that subjects may vary in their motivation to perform well at the enlistment; even if there are both those who are highly and poorly motivated at the enlistment it is easier to underperform. Hence, we are typically worried that some are systematically underperforming in the hope to escape the military service, something that would weaken the estimated transmission in abilities. In Appendix Table A1, we therefore re-estimate our IV estimates (with the uncle instrument), truncating the fathers'

\footnotetext{
${ }^{20}$ Apart from coding errors, rounding can induce some noise to the measure as height is reported in integer centimeters. Further, there is a slight variation of the age at the draft between 18 and 19 years of age, height also differs somewhat over the course of the day, and conscripts may stretch more or less when being measured.
} 
ability distribution ( 2 to 4 percent) in the upper and lower tails. The analysis in column two shows the IV estimates when removing individuals with the lowest score on either the cognitive or non-cognitive test, i.e. those scoring 1 on the original 1 to 9 scale used by the military when aggregating test results. When trimming the lower tail of the distribution, the father-son correlation for cognitive abilities raises to 0.50 and the correlation for noncognitive ability rises to 0.45 . If we instead remove individuals with the highest score on either test the father-son correlation also increases slightly in both ability dimensions (column three). When trimming both the upper and lower tails of the distribution (column four), we find that the estimated father-son correlations increases even further: to 0.51 and 0.48 for cognitive and non-cognitive ability respectively. Since the measured intergenerational transmission in abilities increases symmetrically when we truncate the upper and lower tails of the ability distribution, we interpret this as the intergenerational correlation in skills being lower in the tails due to a mean reversion across generations, rather than there being individuals in both tails who are systematically over- and underperforming. As it is virtually impossible to over-perform at these tests by other means than by chance, we do not think that motivational factors are a major problem in our analysis. Another case in point here is that the intergenerational correlation between fathers cognitive abilities at age 13 (the no-stakes ETF evaluation) and sons at age 18 (the enlistment evaluation) is 0.35 , identical to the OLS estimate using fathers in the uncle-sample. ${ }^{21}$

A similar issue is whether there is a joint motivational factor across brothers towards the enlistment process. This would mean a systematic measurement error, shared between brothers, which would overstate the brother correlation in the first stage regression, and thus bias the IV estimates downwards. The fact that the IV estimates in Table 2 yields the same results when using the father's early ability instrument, as when using the uncle instrument,

\footnotetext{
${ }^{21}$ Details are available from the authors upon request. The correlation between the cognitive evaluations from enlistment and from the ETF-survey is 0.74 among the 6,982 fathers for whom we have data from both sources.
} 
reassures us that a systematic motivation component in the measurement error is at most a limited problem. After all, the test taken at age 13 is set in a very different environment and is without any stakes for the test taker.

A final concern is whether or not our results are sensitive to selection issues induced by the available sampling frame. Up until the late 1990's essentially all Swedish men underwent the whole enlistment procedure, thereby making selection an irrelevant problem of this study. However, as mentioned in section three, the demand for enlisted men decreased in the early 2000's and all men no longer were enlisted. Even though no official documentation suggests that being enlisted is anything but random, this raises some concerns regarding the representativeness of the sample. In order to investigate whether such potential selection biases our results we re-estimate the instrumented father-son correlations for different subsamples.

These estimates are reported in Appendix Table A2. The first column includes the whole sample and shows, as before, a father-son correlation in cognitive abilities of 0.48 . In the next column, we restrict the sample to sons being born prior to 1983, i.e. during a period for which selection is not a problem. The estimate for the restricted sample is slightly higher than in the full sample, 0.49. Columns three and four repeats this exercise for non-cognitive abilities and again we find the correlation in the full sample to be slightly lower than in the pre-1983 sample; 0.43 compared to 0.45 . Thus, selection problems appear to be small and, if anything, causes us to slightly underestimate the true intergenerational ability correlations.

In the last two columns of Table A2, we take a different approach to analyze the selection patterns and regress the sons' GPA at age 16 on their fathers' instrumented cognitive and noncognitive abilities. In column five, this is done only for sons who were enlisted while column six includes both those who drafted and those who did not go through the draft. There is no difference in the estimated coefficients for fathers' cognitive abilities between the samples, 
and there is only a slight difference in the estimates for non-cognitive abilities: in the full sample, the estimate is 0.30 , compared an estimate of 0.27 for the enlistment-only sample. We thus conclude that selection is a minor issue.

All these robustness test give no evidence of a systematic biases caused by motivational factors or changes in sample, and we find that virtually the same IV estimates for the fatherson correlation when using the two different sets of instruments. Based on the results, we also conclude that the IV and OLS estimates are likely to capture the same underlying parameter. Hence, we feel confident that the ability of uncles is a valid instrument when estimating the intergenerational correlations in abilities.

\section{$5 \quad$ Ability correlations using both parents}

So far we have only studied father-son correlations even though both parents presumably are important for the transmission of abilities to their children. The focus on fathers is due to data limitations that we share with several other studies on intergenerational ability correlations. Whether or not the inclusion of mothers is important crucially depends on the degree of assortative mating. If mothers' and fathers' abilities are highly correlated, using abilities for one parent would be sufficient to estimate the full intergenerational correlation between parents and sons. Rather than assuming perfect assortative mating, we generalize our methodological strategy and bring mothers into the analysis by predicting maternal abilities using the enlistment records of their brothers. We then proceed to estimate the intergenerational correlations between sons and both of their parents. This analysis is solely based on the larger uncle-sample, having documented the validity of the uncle instrument in section 4. 


\subsection{Deriving maternal abilities}

In order to derive maternal abilities, we use the idea behind the uncle instrument to predict abilities for both parents using the first stage relation; that is, we use enlistment ability measures of both paternal and maternal uncles. For fathers we can again use the usual two stage procedure, by first estimating the sibling correlation between brothers in equation (4) and plugging the predicted value of fathers' abilities into equation (1). Since we do not observe mothers' abilities we cannot obtain a direct estimate of the first stage equation for mothers. However, if we have an estimate of the sibling correlation between brothers and sister at age 18, $\hat{\rho}_{18}{ }^{\text {brother-sister }}$, from some other source, we could still predict the abilities of mothers from maternal uncles as:

$$
\hat{Y}_{j}^{\text {mother }}=\hat{\pi}+\hat{\rho}_{18}^{\text {brother-sister }} Y_{j}^{\text {maternaluncle }}
$$

We could then plug $\hat{Y}_{i}^{\text {mother }}$ into the second stage relation (1). ${ }^{22}$ To perform this exercise, we need an estimate for $\hat{\rho}_{18}{ }^{\text {brother-sister }}$. If ability correlations between siblings of opposite gender were the same as correlations between same-gender siblings, deriving the implied ability scores for mothers using their brothers' abilities would be a trivial exercise. Rather than just assuming that sibling correlations display such a pattern, we use alternative sources of data to produce an estimate of the gender specific sibling correlations.

To do so, we scale the brother correlations from equation (4) by a factor equal to the relative sister-brother to brother-brother correlation for each assessed ability. These relative correlations are estimated using sources of data where we can observe both men and women. More specifically, we construct the estimate of the brother-sister correlation to be used in the first stage prediction of mother's abilities as follows:

\footnotetext{
${ }^{22}$ Note that we do not have any estimate of the $\pi$-parameter, but this term will be captured by the estimated constant in the second stage regression.
} 


$$
\hat{\rho}_{18}^{\text {brother-sister }}=\hat{\rho}_{18}^{\text {brother }} \frac{\hat{\rho}_{18, k}^{\text {brother-sister }}}{\hat{\rho}_{18, k}^{\text {brother }}}, k=13,16 .
$$

For cognitive skills we have ability evaluations at age 13 from the EFT-study for a sample of both boys and girls. Using these data we first regress sisters' cognitive ability at age 13 on their brothers' cognitive ability at the enlistment at age 18 to obtain the brother-sister correlation $\hat{\rho}_{18,13}{ }^{\text {brothersister }}$. Next, we obtain $\hat{\rho}_{18,13}{ }^{\text {brother }}$ by regressing the cognitive ability at age 13 of one brother on his brother's cognitive ability at the enlistment. Relating the brothersister correlation to the brother correlation then gives us the scaling factor for cognitive ability. In the first column of Appendix Table A3, we find the sibling correlation in cognitive abilities between men for whom we have an ability evaluation at age 13 and their brothers' cognitive enlistment evaluation to be 0.41 . In column two, we find the estimate of the same relation between women's cognitive ability at age 13 and their brothers' enlistment evaluation at age 18 to be 0.38 . This shows that the relative correlation in cognitive abilities for siblings of opposite sex compared to same sex siblings is 0.92 .

Estimating gender differences in non-cognitive sibling correlations is somewhat trickier as we do not have any direct measure of non-cognitive abilities for women at our disposal. What we do have, however, is the GPA from the last year of compulsory school in Sweden, i.e. the year the students' turns 16 . These grades are supposed to reflect how well students perform relative to national standards and grade-setting is aided by standardized national achievement tests in Swedish, English, and Mathematics. GPA records are available from 1988 and we standardize them by year. The GPA-results are used by students to apply for upper-secondary education and they reflect both cognitive and non-cognitive abilities. ${ }^{23}$ In order to obtain a scaling factor for non-cognitive abilities — and an additional estimate of the scaling factor for

\footnotetext{
${ }^{23}$ Regressing an individual's GPA at age 16 on his cognitive and non-cognitive abilities at the enlistment yields a coefficient of $0.56(0.002)$ on cognitive abilities and $0.19(0.002)$ on non-cognitive abilities (standard errors in parentheses). The number of observations in this regression is 232567 .
} 
cognitive abilities—we regress boys' and girls' GPA scores on their brothers' enlistment evaluations. This gives us $\hat{\rho}_{18,16}{ }^{\text {brother }}$ and $\hat{\rho}_{18,16}{ }^{\text {brother-sister }}$, respectively.

As can be seen in the third column of Table A3, male students' GPA-results are strongly related to their brother's cognitive and non-cognitive ability evaluations at the enlistment. ${ }^{24}$ The same is true for female students even though the point estimates differ slightly. By comparing the relative size of point estimates of the importance of brothers' cognitive abilities for the GPA, we find the correlation in cognitive abilities between brothers and sisters to be 0.92 relative to that between brothers. This is close to identical to the relative sibling correlations in cognitive abilities obtained from the estimates in columns one and two. Similarly, the relative sibling correlation in non-cognitive abilities from columns three and four is found to be $0.93 .^{25}$

Based on these estimates, we assume that the scaling factor (the brother-sister correlation relative to the brother-brother correlation) is 0.92 for cognitive abilities and 0.93 for noncognitive abilities. Using these estimates of the relative gender correlations, we calculate the brother-sister correlation at age 18 in the first-stage relation (6) for both cognitive and noncognitive abilities. We then predict the cognitive and non-cognitive abilities for both fathers and mothers using the abilities of paternal and maternal uncles with enlistment records. ${ }^{26}$

\footnotetext{
${ }^{24}$ We include the brother's cognitive and non-cognitive ability measures simultaneously, since GPA reflects both types of abilities. However, the relative correlations for brother-brother and brother-sister are more or less unchanged when entering each ability separately.

${ }^{25}$ There is no consensus regarding the relative correlation in personality traits between same-sex and different-sex siblings. For example, Eaves et al (1999) report opposite-sex correlations in personality traits to vary substantially relative to brother correlations. The relative correlations are 0.61 (Psychoticism), 0.94 (Extraversion), 1.05 (Lie), and 1.25 (Neuroticism). Lake et al (2000) find the opposite-sex correlation in Neuroticism to be 0.89 relative to the brother correlation in Australia, but 1.25 in the US. This wide range of estimates possibly reflects the fact these studies include a relatively low number of individuals and that the samples are non-representative of the general population.

${ }^{26}$ In the specifications where we include both fathers' and mothers' abilities, column three and six in Table 6, we also need to derive a scaling factor for the mother's brothers-in-law correlation. Using information on compulsory school GPA, it can be noted that this scaling factor also becomes 0.92 and 0.93 for cognitive and non-cognitive abilities, respectively.
} 


\subsection{Results for maternal and paternal abilities}

Having derived abilities for both mothers and fathers, we can now estimate the intergenerational correlation between sons and of both of their parents. When doing so, we require that enlistment records are available for both paternal and maternal uncles. This reduces the sample size to around 25,000 sons. In the first column of Table 6 , we estimate the father-son correlation in cognitive ability using the fathers' predicted ability. Since we are using predicted values, attenuation bias due to measurement error is corrected for. The estimated father-son correlation is 0.51 , where the slight difference to the IV estimates in the previous section is due to the somewhat different sample. In column two, we see that the estimated mother-son correlation in cognitive ability is even higher, 0.59 . The third column shows that the partial correlations for fathers' and mothers' abilities are both somewhat reduced when entered jointly into the regression, indicating some degree of positive assortative mating. Consistent with the bivariate results, the partial correlation between mothers and sons is higher (0.43) than the partial father-son correlation (0.34) when both parents' abilities are entered jointly and the difference between these estimates is statistically significant.

\section{[Table 6]}

For non-cognitive abilities, the mother and father correlations are more similar. The fatherson correlation in non-cognitive abilities is 0.46 (column four), the same as the mother-son correlation in column five. When entered jointly, the partial father-son correlation is 0.33 whereas the partial mother-son correlation is 0.29 and the difference between these estimates is not statistically significant.

The results in this section show that mother-son correlations in cognitive abilities are higher than father-son correlations, while the mother-son and father-son correlations are similar for non-cognitive abilities. Although there is a limited amount of research on 
intergenerational ability correlations that differentiates between the influence of paternal and maternal abilities, these findings for cognitive abilities are broadly consistent with previous findings. Using a representative sample from the German Socio-Economic Panel, Anger and Heineck (2009) and Anger (2010) find no clear pattern regarding size of the relative correlations between children and their respective parents. For example, they find mother-son correlations in cognitive speed to be higher than father-son correlations but when using word fluency as an alternative indicator of cognitive ability the pattern is reversed. A meta-study by Bouchard and McGue (1981) does not report any noteworthy gender differences in cognitive ability correlations between parents and children. Regarding non-cognitive abilities, the metastudy by Loehlin (2005) reports mother-child correlations in personality traits and attitudes to be somewhat higher than father-child correlations.

\section{Parental abilities and long run outcomes of children}

In the previous section we derived predicted values for both parents' abilities and estimated the intergenerational correlations between parents and their sons. In this section, we use these predicted abilities to estimate the relation between parental abilities and the educational and labor market outcomes among their children; i.e. among both sons and daughters. In particular, we estimate the relationship between parental abilities on their children's compulsory school achievement, grade point average, total years of education, earnings, and labor force participation. These estimates will capture a composite effect of the influence from of two components. The first is the ability payoff on the skills transmitted from parents to children. The second is the effects of parental abilities on their children's labor market prospects or educational success, including factors such as residential choice, help with homework, professional networks and so on. 
We perform this analysis separately for sons and daughters, thus allowing mothers' and fathers' abilities to have different impact on male and female offspring. Such differences can be due to either a gender specific transmission of parental abilities to their children or that the same ability has different payoffs for men and women. While there is evidence that the same ability can have different payoffs for women and men, ${ }^{27}$ less is known concerning the relative importance of paternal and maternal ability transmission. ${ }^{28}$ Our findings in the previous section indicate that the mother-son correlation in cognitive ability is stronger than father-son correlation but unfortunately our data does not allow us to perform the same analysis for daughters. Educational and labor market outcomes are, however, available both for sons and daughters. The data restrictions are somewhat different in this part of the analysis. We only require the children to have a paternal uncle and a maternal uncle with a valid enlistment record. We can therefore predict cognitive and non-cognitive abilities also for fathers and mothers born before 1950. Further, in order for these long-term outcomes to be representative for life success, we require the labor market outcomes and years of schooling to be observed when sons and daughters are between 30 and 40 years old.

In Table 7 we present the results for educational outcomes for sons and daughters. In columns (1) of the top panel, we regress standardized test scores on paternal abilities. The test scores reflect academic achievement in English, Swedish and mathematics at age 16. The association between cognitive abilities and student achievement is strong: 0.47 for sons and 0.45 for daughters. The relation between test scores and non-cognitive ability is considerably weaker: 0.09 among sons and 0.14 among daughters. Columns (2) perform the same analysis

\footnotetext{
${ }^{27}$ Heckman et al. (2006) provides an analysis of gender specific payoffs of cognitive and non-cognitive abilities. Further, Mueller and Plug (2006) find that women with an antagonistic personality are at a substantial earnings disadvantage compared to women who are more agreeable. For men, this pattern is reversed. Nyhus and Pons (2005) report similar findings.

${ }^{28}$ There is a large literature discussing the relative impact of fathers' and mothers' educational attainment on child outcomes. The methodological challenge of this literature is to distinguish between the effects of the parents' abilities from the effects of the educational attainment, per se (e.g. Behrman and Rosenzweig, 2002; Currie and Moretti, 2003; Plug, 2004, Black et al, 2005).
} 
using maternal abilities. The association between maternal cognitive ability and achievement is stronger for sons $(0.51)$ than for daughters $(0.43)$, while the reverse is true for non-cognitive abilities ( 0.10 for sons and 0.20 for daughters). In columns (3), we employ bother maternal and paternal abilities simultaneously and find that the same patterns hold: mothers' cognitive abilities are relatively more important for sons while mothers' non-cognitive abilities are relatively important for daughters and there is no difference between sons and daughters for fathers' abilities. The size of the estimated effects is large and a child whose both parents have abilities one standard deviation above mean on average achieve 0.8 standard deviations above mean.

[Table 7]

In the middle panel, sons' and daughters' grade point average (GPA) from the last year of compulsory school (at age 16) is used as the dependent variable. The patterns are similar as for test score results, although parents' non-cognitive abilities are more important for grades than for test scores. Again, the total effect of having two parents one standard deviation above mean is associated with approximately 0.8 standard deviations higher GPA. Given these results, it is unsurprising that we find the strong relation between total years of schooling and parental abilities that is presented in the bottom panel. Here there are some interesting gender differences, however: Both paternal and maternal cognitive abilities are more strongly related to sons' than daughters' total years of schooling while both parents' non-cognitive abilities are more important for daughters than for sons. One possibility is that this is due to differences in types of higher education that men and women chose, but it is beyond the scope of this paper to further analyze these differences.

In Table 8, we turn to the relation between parental abilities and their children's labor market outcomes. In the top panel, we regress annual earnings (as share of mean earnings among the sample of sons and daughters, respectively) on fathers' and mothers' abilities. 
What stands out is that parental non-cognitive abilities are substantially more important than their cognitive abilities for the earnings of their children. Sons whose parents have abilities one standard deviation above the mean on average earn almost 25 percent more and the corresponding number among daughters is 20 percent. The middle panel shows that one of the reasons behind this result is that parental non-cognitive abilities are strong predictors of labor force participation, while cognitive abilities are not. This relation holds for both sons and daughters, and for both fathers' and mothers' non-cognitive abilities. Among sons, a one standard deviation increase in either fathers' or mothers' non-cognitive ability is associated with about a six percentage point higher probability of being employed. Among daughters, a one standard deviation increase in fathers' non-cognitive abilities increases the probability that daughters participate in the labor force by 9 percentage points and the corresponding figure for mothers is 6.4 percentage points. The relation between parental cognitive abilities and labor force participation is on the other hand weak and sometimes even negative, albeit not statistically significant.

[Table 8]

In the bottom panel, we estimate the relation between log earnings and parental abilities, meaning that we only estimate these relations among sons and daughters with positive earnings. For sons, the relation between log income and the cognitive and non-cognitive abilities of their fathers is 0.053 and 0.054 , respectively. As for mothers' abilities, the point estimate for cognitive abilities is 0.036 and 0.05 for non-cognitive. The estimated correlation between daughters' log income and parental non-cognitive abilities suggests a somewhat different pattern: the estimate for fathers' cognitive abilities is 0.062 while the association is close to zero for non-cognitive abilities. The relative importance of cognitive abilities also holds true when we turn to maternal abilities: the point estimate is 0.053 for cognitive and 0.016 (not statistically significant) for non-cognitive abilities. 
In sum, we find that both parents' cognitive and non-cognitive abilities are strongly related to the educational and labor market outcomes of their offspring. Parental cognitive abilities are relatively more important for schooling outcomes, while parental non-cognitive abilities are particularly important for labor force participation. These results are fully in line with the findings that Lindqvist and Vestman (2011) report for men, using men's own cognitive and non-cognitive abilities. Our results thus suggest that these findings for men can be generalized to women but there are some noteworthy gender differences. First of all, parental cognitive abilities are, relative to non-cognitive abilities, more important for educational outcomes for sons than for daughters, while parental cognitive abilities are relatively important for female earnings - provided that the women are in the labor force.

\section{Conclusions}

This paper makes several distinct contributions to the literature on the intergenerational transmission of cognitive and non-cognitive abilities. First, we compare intergenerational correlations in cognitive and non-cognitive abilities using large and representative samples of men who are evaluated using the same methods and at the same age. Second, we correct for measurement error bias using two different sets of instruments. In particular, we make a methodological contribution by demonstrating that the ability evaluations of a father's brother (a child's uncle) can be used as instruments to correct for measurement error in the father's abilities. Third, we bring mothers into the analysis by predicting their abilities using the ability evaluations of maternal uncles. Forth, we estimate the importance of the transmission in abilities from both parents for outcomes later in life, both for sons and daughters.

We find evidence of measurement error bias in both ability dimensions and once this bias is corrected for, the intergenerational transmission of non-cognitive abilities is almost as high as that of cognitive skills. This is in contrast to previous research which indicates that the 
transmission of non-cognitive abilities between generations is substantially lower than that of cognitive abilities. That measurement error problems are more severe when evaluating noncognitive than cognitive abilities is unlikely to be a unique feature of our data and hence our findings have bearing on the interpretation of the results in the existing literature.

When using the predicted abilities for both parents, we find that the mother-son correlation in cognitive abilities is stronger than the father-son correlation while there is no substantive difference for parental non-cognitive abilities. Finally, we find a strong relation between both parents' cognitive and non-cognitive abilities and several educational and labor market outcomes for both sons and daughters. Parental cognitive abilities are relatively important for schooling outcomes, while parental non-cognitive abilities are particularly important for labor force participation among both men and women. These results show that previous findings regarding the importance of cognitive and non-cognitive abilities for male earnings and labor force participation (Lindqvist and Vestman, 2011) are likely to generalize to women. Some noteworthy gender differences are found, however: Parental cognitive abilities are, relative to non-cognitive abilities, more important for educational outcomes for sons than for daughters, while parental cognitive abilities are relatively important for female earnings - provided that the women are in the labor force. A better understanding of these differences is an obvious question for future research.

There is a general perception that non-cognitive abilities are relatively malleable, and hence a more appropriate target for policy interventions than cognitive abilities (Carneiro and Heckman, 2003; Knudsen et al, 2006; Cunha and Heckman, 2008). Our finding that families play an important role in shaping both cognitive and non-cognitive abilities raises some doubts concerning this view. Potentially, our results can explain the disappointing record of programs aimed at raising academic achievement and labor market outcomes by improving 
non-cognitive skills among students. ${ }^{29}$ Before drawing any strong conclusion on these matters, however, more research is clearly needed. In particular, it should be stressed that our study presents a descriptive analysis of intergenerational correlations which does not disentangle the mechanisms through which these correlations arise. ${ }^{30}$ A more detailed understanding of these mechanisms may very well end up showing that the targeting of noncognitive abilities is indeed the appropriate policy. Whatever these appropriate policies may be, the finding that they are likely to have an impact on both current and future generations only highlight the importance of research in this field.

\footnotetext{
${ }^{29}$ See Holmlund and Silva (2009) and the references therein.

${ }^{30}$ These mechanisms are likely to include complex interactions between genetic and environmental factors. A recent study by Cesarini (2009) uses mono-zygotic and dizygotic twins, as well as different types of siblings to estimate the family component of-among other things - cognitive and non-cognitive abilities. Cunha and Heckman (2007) provide a perspective on the nature-nurture debate. Using a large sample of adopted children, Björklund et al (2006) find that pre- and postbirth parental characteristics interact when influencing child outcomes.
} 


\section{References}

Anger, S. (2010), "The Intergenerational Transmission of Cognitive and Non-Cognitive Skills" mimeo DIW Berlin.

Anger, S. and G. Heineck (2009), "Do Smart Parents Raise Smart Children? The Intergenerational Transmission of Cognitive Abilities", SOEPpapers 156.

Ashenfelter, O. and A. Krueger (1994), Estimates of the Economic Return to Schooling from a New Sample of Twins, American Economic Review, 84:5, 1157-1173.

Behrman, J. and M. Rosenzweig (2002), "Does Increasing Women's Schooling Raise the Schooling of the Next Generation?”, American Economic Review, 92:1, 323-334.

Björklund, A., K. Hederos Eriksson, and M. Jäntti (2010), ”IQ and Family Background: Are Associations Strong or Weak?", The B.E. Journal of Economic Analysis \& Policy, 10:1 (Contributions), Article 2.

Björklund, A., L. Lindahl, and M. Lindquist (2010), "What More Than Parental Income, Education and Occupation? An Exploration of What Swedish Siblings Get From Their Parents", The B.E. Journal of Economic Analysis \& Policy, Vol. 10:1 (Contributions), Article 102.

Björklund, A., M. Lindahl and E. Plug (2006), "The Origins of Intergenerational Associations: Lessons From Swedish Adoption Data", Quarterly Journal of Economics, 121:3, 999-1028.

Black, S. and P. Devereux (2010), "Recent Developments in Intergenerational Mobility, NBER Working Paper 15889.

Black, S., P. Devereux, and K. Salvanes (2005), “Why the Apple Doesn't Fall Far: Understanding Intergenerational Transmission of Human Capital”, American Economic Review, 95:1, 437449.

Black, S., P. Devereux, and K. Salvanes (2007), “Older and Wiser? Birth Order and IQ of Young Men”, NBER Working Paper 13237.

Black, S., P. Devereux, and K. Salvanes (2009), "Like Father Like Son? A Note on the Intergenerational Transmission of IQ Scores", Economics Letters, 105, 138-140.

Blanden, J., P. Gregg, and L. MacMillan (2007), “Accounting for Intergenerational Income Persistence: Noncognitive Skills, Ability and Education”, Economic Journal, 117, C43-C60

Borghans, L., A.L. Duckworth, J.J. Heckman, and B. ter Weel (2008), “The Economics and Psychology of Personality Traits", Journal of Human Resources, 43:4, 972-1059.

Bouchard, T. and M. McGue (1981), "Familial Studies of Intelligence: A Review", Science, 212:4498, 1055-1059. 
Bowles, S. and H. Gintis (2002), "The Inheritance of Inequality", Journal of Economic Perspectives, 16:3, 3-30.

Bowles, S., H. Gintis and M. Osborne (2001), "The Determinants of Earnings: A Behavioural Approach", Journal of Economic Literature, 39, 1137-1176.

Brown, S., J. McHardy, and K. Taylor (2011), “Intergenerational Analysis of Social Interaction”, IZA DP 5621.

Carneiro, P and J. Heckman (2003): "Human Capital Policy", in J. Heckman and A. Krueger (eds.), Inequality in America: What Role for Human Capital Policies?, Cambridge, Mass: MIT Press.

Cesarini, D. (2009), "Family Influence on Productive Skills, Human Capital and Lifecycle Income", mimeo MIT.

Cunha, F. and J. Heckman (2007), “The Technology of Skill Formation”, American Economic Review, 97:2, 31-47.

Cunha, F. and J. Heckman (2008), "Formulating, Identifying and Estimating the Technology of Cognitive and Noncognitive Skill Formation”, Journal of Human Resources, vol. 43:4, 738782.

Currie, J. and E. Moretti (2003), “Mother's Education and the Intergenerational Transmission of Human Capital", Quarterly Journal of Economics, 118:4, 1495-1532.

Dohmen, T., A. Falk, D. Huffman, and U. Sunde (2008), “The Intergenerational Transmission of Risk and Trust Attitudes", CESifo WP No. 2307.

Eaves, L., A. Heath, N. Martin, H. Maes, M. Neale, K. Kendler, K. Kirk, and L. Corey (1999), "Comparing the Biological and Cultural Inheritance of Personality and Social Attitudes in the Virginia 30000 Study of Twins and Their Relatives", Twin Research, 2:2, 62-80.

Heckman, J., J. Stixrud, and S. Urzua (2006), "The Effects of Cognitive and Noncognitive Abilities on Labor Market Outcomes and Social Behavior", Journal of Labor Economics, 24:3, 411-482.

Hirvonen. L. (2009), “Accounting for Intergenerational Earnings Persistence: Can We Distinguish Between Education, Skills, and Health?”, PhD-thesis Stockholm University.

Holmlund, H. and O. Silva (2009), "Targeting Non-Cognitive Skills to Improve Cognitive Outcomes: Evidence from a Remedial Education Intervention”, IZA Discussion Paper No. 4476.

Imbens, G. and J. Angrist (1994), "Identification and Estimation of Local Average Treatment Effects", Econometrica, 62, 467-75. 
Knudesn, E., J. Heckman, J. Cameron and J. Shonkoff (2006), "Economic, Neurobiological and Behavioral Perspectives on Building America's Future Workforce”, NBER WP 12298.

Lake, R., L. Eaves, H. Maes, A. Heath, and N. Martin (2000), "Further Evidence against the Environmental Transmission of Individual Differences in Neuroticism from a Collaborative Study of 45,850 Twins and Relatives on Two Continents", Behavior Genetics, 30:3, 223-233.

Lindqvist, E. and R. Vestman (2011), “The Labor Market Returns to Cognitive and Noncognitive Ability: Evidence from the Swedish Enlistment", American Economic Journal: Applied Economics.

Loehlin, J. (2005), "Resemblance in Personality and Attitudes Between Parents and Their Children: Genetic and Environmental Contributions", in S. Bowles, H. Gintis, and Melissa Osborne Groves (eds.) Unequal Chances. Family Background and Economic Success, Russell Sage, Princeton University Press.

Mueller, G. and E. Plug (2006), "Estimating the Effect of Personality on Male and Female Earnings", Industrial and Labor Relations Review, 60:1, 3-22.

Nyhus, E. and E. Pons (2005), “The Effects of Personality on Earnings”, Journal of Economic Psychology, 26, 363-384.

Osborne Groves, M. (2005), "Personality and the Intergenerational Transmission of Economic Status", in S. Bowles, H. Gintis, and M. Osborne Groves (eds.) Unequal Chances. Family Background and Economic Success, Russell Sage, Princeton University Press.

Plomin, R., and F. Spinath (2004), "Intelligence: Genetics, Genes, and Genomics”, Journal of Personality and Social Psychology, 86:1, 112-129.

Plug, E. (2004), “Estimating the Effect of Mother's Schooling on Children's Schooling Using a Sample of Adoptees", American Economic Review, 94:1, 358-368.

Solon, G. (1999), "Intergenerational Mobility in the Labor Market", in Ashenfelter, O. and D. Card (eds.) Handbook of Labor Economics, vol 3.

Wilhelm, M.O., E. Brown, P.M. Rooney, and R. Steinberg (2008) "The Intergenerational Transmission of Generosity", Journal of Public Economics, 92, 2146-2156. 


\section{Appendix A: Tables}

Table A1 Intergenerational correlations, addressing cheating, floor and ceiling effects

\begin{tabular}{|c|c|c|c|c|}
\hline Dependent variable: & $\begin{array}{l}\text { Son's } \\
\text { ability }\end{array}$ & $\begin{array}{l}\text { Son's } \\
\text { ability }\end{array}$ & $\begin{array}{l}\text { Son's } \\
\text { ability }\end{array}$ & $\begin{array}{l}\text { Son's } \\
\text { ability }\end{array}$ \\
\hline Independent variable: & \multicolumn{4}{|c|}{ Cognitive ability } \\
\hline Father's ability & $\begin{array}{c}0.478 \\
(0.009)\end{array}$ & $\begin{array}{c}0.496 \\
(0.010)\end{array}$ & $\begin{array}{c}0.488 \\
(0.011)\end{array}$ & $\begin{array}{c}0.510 \\
(0.013)\end{array}$ \\
\hline & \multicolumn{4}{|c|}{ Non-cognitive ability } \\
\hline Father's ability & $\begin{array}{c}0.422 \\
(0.015)\end{array}$ & $\begin{array}{c}0.449 \\
(0.017)\end{array}$ & $\begin{array}{c}0.445 \\
(0.017)\end{array}$ & $\begin{array}{c}0.479 \\
(0.020)\end{array}$ \\
\hline \multicolumn{5}{|l|}{ Trimming of fathers ability: } \\
\hline Removing upper tail & & & $\mathrm{X}$ & $\mathrm{X}$ \\
\hline $\mathrm{N}$ & 50,175 & 49,050 & 48,649 & 47,527 \\
\hline
\end{tabular}

Table A2 Intergenerational correlations, addressing sample selection of sons

\begin{tabular}{|c|c|c|c|c|c|c|}
\hline Dependent variable: & $\begin{array}{l}\text { Son's } \\
\text { cognitive }\end{array}$ & $\begin{array}{l}\text { Son's } \\
\text { cognitive }\end{array}$ & $\begin{array}{c}\text { Son's } \\
\text { non-cognitive }\end{array}$ & $\begin{array}{c}\text { Son's } \\
\text { non-cognitive }\end{array}$ & $\begin{array}{c}\text { Son's } \\
\text { GPA at age } 16\end{array}$ & $\begin{array}{c}\text { Son's } \\
\text { GPA at age } 16\end{array}$ \\
\hline $\begin{array}{l}\text { Independent variable: } \\
\text { Father's cognitive ability }\end{array}$ & $\begin{array}{c}0.478 \\
(0.009)\end{array}$ & $\begin{array}{c}0.492 \\
(0.013)\end{array}$ & & . & $\begin{array}{c}0.327 \\
(0.014)\end{array}$ & $\begin{array}{c}0.327 \\
(0.012)\end{array}$ \\
\hline Father's non-cognitive ability & . & . & $\begin{array}{c}0.422 \\
(0.015)\end{array}$ & $\begin{array}{c}0.443 \\
(0.020)\end{array}$ & $\begin{array}{c}0.265 \\
(0.020)\end{array}$ & $\begin{array}{c}0.299 \\
(0.017)\end{array}$ \\
\hline $\begin{array}{r}\text { Son's year of birth: } \\
\text { Before } 1988\end{array}$ & $\mathrm{X}$ & & $\mathrm{X}$ & & $\mathrm{X}$ & $\mathrm{X}$ \\
\hline Before 1983 & & $\mathrm{X}$ & & $\mathrm{X}$ & & \\
\hline \multicolumn{7}{|l|}{ Son's draft status } \\
\hline Drafted & $\mathrm{X}$ & $\mathrm{X}$ & $\mathrm{X}$ & $\mathrm{X}$ & $\mathrm{X}$ & $\mathrm{X}$ \\
\hline Not drafted & & & & & & $\mathrm{X}$ \\
\hline $\mathrm{N}$ & 50,172 & 28,337 & 50,214 & 28,337 & 48,768 & 71,953 \\
\hline
\end{tabular}

Notes: The ability measures have been standardized by year of draft. The GPA at age 16 has been standardized by year of completion. The father's ability is instrument by the uncle's ability. Standard errors adjusted for clustering on the father are in parentheses. 
$\underline{\text { Table A3 Sibling correlations }}$

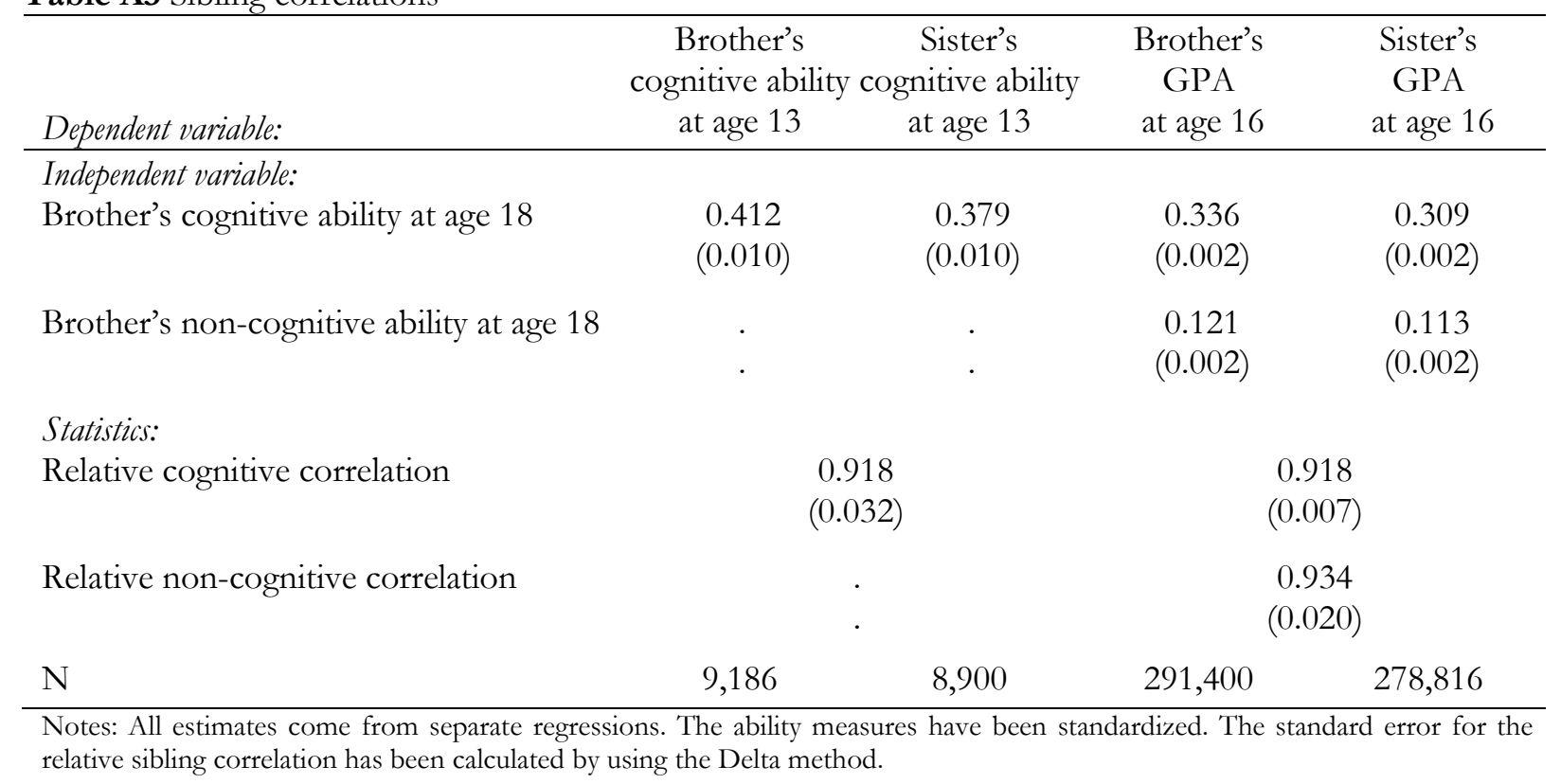




\section{Appendix B. Modelling the measurement error}

In section 2 we discuss whether the local average treatment effect captured by the uncle instrument reflects is representative of the average treatment effect captured by the OLS. In this appendix, we show that if the IV estimates using the uncle instrument and the father's earlier ability instrument give the same results, both instruments capture the same parameter as the OLS. We here abstract from the measurement error.

\section{The uncle instrument}

Consider that the production of the underlying latent ability is a linear function of genetic $(\mathrm{G})$ and environmental factors (E), where some parts are shared (S) between brothers and some part are not shared (NS). Specifically, we characterize the latent ability of individual $i$ belonging to family $j$ as:

$$
Y_{j}^{*_{i}}=Y_{j S}^{*_{i} G}+Y_{j N S}^{*_{i} G}+Y_{j S}^{*_{i} E}+Y_{j S}^{*_{i} E}
$$

where there are no complementarities across genetic and environmental components or between shared and non-shared components. If we further assume that the intergenerational transmission is the same for shared (non-shared) genetic (environmental) factors we can write the model of intergenerational transmission as:

$$
Y_{j}^{* \text { son }}=\alpha+\beta Y_{j}^{* \text { father }}+\varepsilon_{j}=\alpha+\beta^{G} Y_{j, S}^{* \text { father, } G}+\beta^{G} Y_{j, N S}^{* \text { father, } G}+\beta^{E} Y_{j, S}^{* \text { father }, E}+\beta^{E} Y_{j, N S}^{* \text { father,E}}+\varepsilon_{j},
$$

where:

$$
p \lim \hat{\beta}_{\text {OLS }}=\beta^{G} \frac{V\left(Y_{j, S}^{* \text { father, }, G}\right)+V\left(Y_{j, N S}^{* \text { father }, G}\right)}{V\left(Y_{j}^{* \text { father }}\right)}+\beta^{E} \frac{V\left(Y_{j, S}^{* \text { father }, E}\right)+V\left(Y_{j, N S}^{* \text { father, }, E}\right)}{V\left(Y_{j}^{* \text { father }}\right)} .
$$

In effect, the transmission of abilities over generations will be a sum of the intergenerational transmission of the genetic and the environmental component weighted by the relative share of the variation in fathers' abilities coming from these two sources. 
The uncle instrument, $Z_{j}^{* i \text {,uncle }}$, captures only the variation in the determinants of the latent ability that is shared between brothers; that is $Z_{j}^{*_{i} \text {,uncle }}=Y_{j S}^{* i G}+Y_{j S}^{*_{i} E}$. Using the uncle instrument thus yields:

$$
p \lim \hat{\beta}_{I V}^{\text {uncle }}=\beta^{G} \frac{V\left(Y_{j, S}^{* \text { father }, G}\right)}{V\left(Y_{j, S}^{* \text { father,G}}\right)+V\left(Y_{j, S}^{* \text { father }, E}\right)}+\beta^{E} \frac{V\left(Y_{j, S}^{* \text { father }, E}\right)}{V\left(Y_{j, S}^{* \text { father,G}}\right)+V\left(Y_{j, S}^{* \text { father }, E}\right)} .
$$

We see here that for the local average treatment effect—when using the uncle instrumentto capture the same effect as the OLS we must (i) either have that the shared parts of brother's abilities have the same relative genetic and environmental determinants as the non-shared parts:

$$
\frac{V\left(Y_{j, S}^{* \text { father }, G}\right)}{V\left(Y_{j, S}^{* \text { father,G})+V\left(Y_{j, S}^{*} \text { father, } E\right.}\right)}=\frac{V\left(Y_{j, S}^{* \text { father }, G}\right)+V\left(Y_{j, N S}^{* \text { father, }, G}\right)}{V\left(Y_{j}^{* \text { father }}\right)},
$$

or (ii) that the intergenerational transmission is the same for the genetic and environmental components, $\beta^{G}=\beta^{E}$.

\section{The fathers' early ability instrument}

When we instead use fathers' own ability at age 13 as an instrument, we model the underlying latent ability as having three separate determinants: a genetic part; a part capturing all environmental influences on ability up to age 13; an part capturing additional environmental influences between age 13 and 18 . We characterize the production function for abilities as a linear function without complementarities between the parts as:

$$
Y_{j}^{*_{i}}=Y_{j}^{*_{i} G}+Y_{j 13}^{*_{i E}}+Y_{j 13-18}^{*_{i} E} .
$$

If we assume that the intergenerational transmission of the environmental factors up to age 13 and between age 13 and 18 is the same, $\beta^{E}$, we have that:

$$
p \lim \hat{\beta}_{O L S}=\beta^{G} \frac{V\left(Y_{j}^{* \text { father, } G}\right)}{V\left(Y_{j}^{* \text { father }}\right)}+\beta^{E} \frac{V\left(Y_{j, 13}^{* \text { father }, E}\right)+V\left(Y_{j, 13-18}^{* \text { father }, E}\right)}{V\left(Y_{j}^{* \text { father }}\right)} .
$$

The father's early ability instrument, $Z_{j}^{*, 13}$, utilizes a measurement of the father's ability at age 13. This instrument therefore captures all genetically determinants of the father's ability 
and all environmental determinants up to age 13 ; that is $Z_{j}^{*_{i, 13}}=Y_{j}^{*_{i} G}+Y_{j 13}^{*_{i} E}$. Using the father's own ability as an instrument gives us:

$$
p \lim \hat{\beta}_{I V}^{13}=\beta^{G} \frac{V\left(Y_{j}^{* \text { father }, G}\right)}{V\left(Y_{j}^{* \text { father,G}}\right)+V\left(Y_{j, 13}^{* \text { father }, E}\right)}+\beta^{E} \frac{V\left(Y_{j, 13}^{* \text { father }, E}\right)}{V\left(Y_{j}^{*} \text { father,G }\right)+V\left(Y_{j, 13}^{* \text { father, } E}\right)} .
$$

Now, for the OLS and the IV—-when using the father's early ability instrument — to capture the same effect we either need (i) the environmental influence between ages 14 and 18 on the abilities measured at enlistment to be negligible, $V\left(Y_{j, 14-18}^{* \text { fatherE }}\right)=0$, or (ii) the intergenerational transmission of the genetic and environmental components to be the same, $\beta^{G}=\beta^{E}$.

\section{When does the IV represent the OLS?}

The above discussion shows that if the IV estimates when using the uncle instrument and the father's own ability at age 13 are identical; the IV captures the same parameter as OLS. The reason is that, in our setting, the two instruments will only generate the same estimates under two different circumstances. First, this will occur if the intergenerational transmission of genetic and environmental factors is identical $\beta^{G}=\beta^{E}$. The second possibility for this to happen is that the environmental influence between ages 14 and 18 on the abilities measured at enlistment is negligible and that the shared parts of brother's abilities have the same relative determinants as the non-shared parts. In either case, we have shown that the local average treatment effect when using either instrument represents the average treatment effect captured by the OLS. 
Table 1. Descriptive statistics

\begin{tabular}{|c|c|c|c|c|c|}
\hline & \multicolumn{2}{|c|}{ ETF-sample } & \multicolumn{3}{|c|}{ Uncle-sample } \\
\hline & Sons & Fathers & Sons & Fathers & Paternal uncles \\
\hline $\begin{array}{l}\text { Variables: } \\
\text { Year of birth }\end{array}$ & $\begin{array}{r}1980.33 \\
(3.78)\end{array}$ & $\begin{array}{r}1953.00 \\
(0.00)\end{array}$ & $\begin{array}{r}1981.31 \\
(3.91)\end{array}$ & $\begin{array}{r}1954.64 \\
(2.52)\end{array}$ & $\begin{array}{r}1955.46 \\
(2.68)\end{array}$ \\
\hline Age at draft & $\begin{array}{l}18.19 \\
(0.33)\end{array}$ & $\begin{array}{l}18.73 \\
(0.51)\end{array}$ & $\begin{array}{l}18.21 \\
(0.35)\end{array}$ & $\begin{array}{l}18.51 \\
(0.56)\end{array}$ & $\begin{array}{l}18.44 \\
(0.56)\end{array}$ \\
\hline Cognitive ability at 18 & $\begin{array}{l}0.07 \\
(0.96)\end{array}$ & $\begin{array}{c}0.01 \\
(0.97)\end{array}$ & $\begin{array}{c}0.09 \\
(0.93)\end{array}$ & $\begin{array}{l}-0.03 \\
(0.97)\end{array}$ & $\begin{array}{l}-0.09 \\
(1.00)\end{array}$ \\
\hline Non-cognitive ability at 18 & $\begin{array}{c}0.04 \\
(0.99)\end{array}$ & $\begin{array}{l}0.09 \\
(0.96)\end{array}$ & $\begin{array}{l}0.05 \\
(0.97)\end{array}$ & $\begin{array}{c}0.07 \\
(0.98)\end{array}$ & $\begin{array}{l}-0.02 \\
(0.99)\end{array}$ \\
\hline Cognitive ability at 13 & . & $\begin{array}{c}0.04 \\
(0.99)\end{array}$ & . & . & . \\
\hline $\begin{array}{l}\text { Non-theoretical GPA at } 13 \\
\text { (residual) }\end{array}$ & . & $\begin{array}{c}0.00 \\
(1.00)\end{array}$ & . & . & . \\
\hline $\begin{array}{l}\text { Educational aspirations at } 13 \\
\text { (residual) }\end{array}$ & . & $\begin{array}{c}0.00 \\
(1.00)\end{array}$ & . & . & . \\
\hline $\begin{array}{l}\text { Spend time with friends at } 13 \\
\text { (residual) }\end{array}$ & . & $\begin{array}{c}0.00 \\
(1.00)\end{array}$ & . & . & . \\
\hline $\mathrm{N}$ & 1,889 & 1,465 & 50,214 & 40,277 & 39,599 \\
\hline
\end{tabular}


Table 2 OLS and IV-estimates of intergenerational correlation in abilities - alternative instruments

\begin{tabular}{|c|c|c|c|c|}
\hline Sample: & \multicolumn{2}{|c|}{ ETF-sample } & \multicolumn{2}{|c|}{ Uncle-sample } \\
\hline Dependent variable: & $\begin{array}{c}\text { Son's cognitive } \\
\text { ability }\end{array}$ & $\begin{array}{c}\text { Son's non- } \\
\text { cognitive ability }\end{array}$ & $\begin{array}{c}\text { Son's cognitive } \\
\text { ability }\end{array}$ & $\begin{array}{c}\text { Son's non- } \\
\text { cognitive ability }\end{array}$ \\
\hline & \multicolumn{2}{|c|}{ OLS } & \multicolumn{2}{|c|}{ OLS } \\
\hline $\begin{array}{l}\text { Independent variable: } \\
\text { Father's cognitive } \\
\text { Ability }\end{array}$ & $\begin{array}{c}0.323 \\
(0.023)\end{array}$ & & $\begin{array}{c}0.350 \\
(0.004)\end{array}$ & \\
\hline $\begin{array}{l}\text { Father's non- } \\
\text { cognitive ability }\end{array}$ & & $\begin{array}{c}0.212 \\
(0.024)\end{array}$ & & $\begin{array}{c}0.210 \\
(0.005)\end{array}$ \\
\hline
\end{tabular}

\begin{tabular}{lcccc} 
& \multicolumn{2}{c}{ IV - Father's ability at age 13 } & & IV - Uncle's ability \\
\cline { 2 - 2 } Father's cognitive & 0.423 & & 0.478 & \\
Ability & $(0.031)$ & $0.009)$ & 0.422 \\
Father's non- & & & & $(0.015)$ \\
cognitive ability & & $(0.050)$ & &
\end{tabular}

Statistic:

\begin{tabular}{lcccc} 
Reliability ratio & 0.764 & 0.515 & 0.731 & 0.497 \\
& $(0.078)$ & $(0.209)$ & $(0.017)$ & $(0.021)$ \\
F-test (first stage) & 1713.89 & 9.45 & 10251.65 & 3709.68 \\
$\mathrm{~N}$ & 1,889 & 1,889 & 50,172 & 50,172 \\
\hline
\end{tabular}

Notes: All estimates come from separate regressions. The ability measures have been standardized. Standard errors adjusted for clustering on the father are in parentheses. In the IV-specification, the father's ability has been instrumented with either the father's ability at age 13 or the uncle's ability. Father's non-cognitive ability at age 13 is given by his average verbal, spatial and logical abilities. Father's non-cognitive abilities are given by his non-theoretical school grades, educational aspirations and peer interaction, where the effect of his cognitive abilities at age 13 has been partialled out. The reliability ratios have been calculated by dividing the OLS-estimates by the IV-estimates, and the standard errors have been computed by means of the delta-method. 
Table 3 IV-estimates of intergenerational correlations in both cognitive and non-cognitive abilities

Son's Son's non-

Dependent variable: $\quad$ cognitive ability cognitive ability

Independent variable:

Father's cognitive ability $\quad 0.445 \quad 0.043$

(0.014) (0.015)

Father's non-cognitive ability $\quad 0.069 \quad 0.391$

(0.019) (0.021)

$\mathrm{N} \quad 50,172 \quad 50,172$

Notes: The ability measures have been standardized. Standard errors adjusted for clustering on the father are in parentheses. The father's abilities have been instrumented with the uncle's abilities

Table 4 Intergenerational correlation in abilities - alternative restrictions

\begin{tabular}{lcccc}
\hline Sample: & All & \multicolumn{2}{c}{$\begin{array}{c}\text { Dead or emigrated Dead grandfather } \\
\text { uncle }\end{array}$} & $\begin{array}{c}\text { Dead grandfather } \\
\text { or grandmother } \\
\text { and grandmother }\end{array}$ \\
\hline Model: & \multicolumn{5}{c}{ Panel A. Cognitive abilities } \\
OLS & 0.350 & 0.356 & 0.329 & 0.298 \\
& $(0.004)$ & $(0.049)$ & $(0.012)$ & $(0.056)$ \\
IV & 0.478 & 0.602 & 0.464 & 0.414 \\
& $(0.009)$ & $(0.104)$ & $(0.025)$ & $(0.117)$ \\
Statistic: & & & & \\
Reliability ratio & 0.731 & 0.591 & 0.708 & 0.721 \\
& $(0.017)$ & $(0.131)$ & $(0.047)$ & $(0.244)$ \\
Model: & & Panel B. Non-cognitive abilities & \\
OLS & 0.210 & 0.259 & 0.199 & 0.178 \\
& $(0.005)$ & $(0.058)$ & $(0.013)$ & $(0.061)$ \\
IV & 0.422 & 0.677 & 0.415 & 0.709 \\
& $(0.015)$ & $(0.175)$ & $(0.043)$ & $(0.247)$ \\
Statistic: & & & \\
Reliability ratio & 0.497 & 0.382 & 0.480 & 0.251 \\
& $(0.021)$ & $(0.131)$ & $(0.059)$ & $(0.123)$ \\
N & 50,172 & 311 & 5,777 & 258 \\
\hline
\end{tabular}

Notes: All estimates come from separate regressions. The ability measures have been standardized. The father's abilities have been instrumented with the uncle's abilities. Standard errors adjusted for clustering on the father are in parentheses. The reliability ratios have been calculated by dividing the OLS-estimates by the IV-estimates, and the standard errors have been computed by means of the delta-method. 
Table 5 Instrument validity check: Intergenerational correlations in height

\begin{tabular}{|c|c|c|c|}
\hline \multirow[b]{2}{*}{ Dependent variable: } & \multicolumn{2}{|c|}{ OLS } & \multirow{2}{*}{$\begin{array}{c}\text { IV } \\
\text { Son's } \\
\text { Height }\end{array}$} \\
\hline & $\begin{array}{l}\text { Son's } \\
\text { height }\end{array}$ & $\begin{array}{l}\text { Son's } \\
\text { height }\end{array}$ & \\
\hline Independent variable: & & & \\
\hline Father's height & $\begin{array}{c}0.483 \\
(0.004)\end{array}$ & $\begin{array}{c}0.477 \\
(0.005)\end{array}$ & $\begin{array}{c}0.500 \\
(0.008)\end{array}$ \\
\hline Uncle's height & . & $\begin{array}{c}0.012 \\
(0.005)\end{array}$ & . \\
\hline $\mathrm{N}$ & 52,973 & 52,973 & 52,973 \\
\hline
\end{tabular}

Notes: The height has been standardized by year of draft. Standard errors adjusted for clustering on the father are in parentheses. In the IV-specification, the father's height is instrument by the uncle's height, and the sample is restricted to sons who have at least one uncle. 
Table 6 Father-son and mother-son correlations

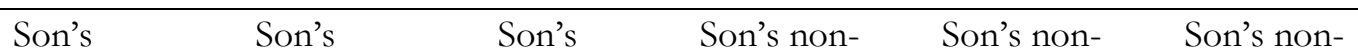

Dependent variable: $\quad$ cognitive ability cognitive ability cognitive ability cognitive ability cognitive ability cognitive ability

Independent variable:

Father's cognitive ability

$0.508 \quad 0.338$

(0.014)

(0.017)

Mother's cognitive ability

$\begin{array}{ccc}. & 0.589 & 0.434 \\ . & (0.015) & (0.019)\end{array}$

Father's non-cognitive ability

$(0.019)$

Mother's non-cognitive ability

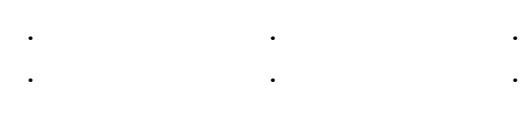

0.46

. $\quad(0.021)$

0.336

$\begin{array}{ll}\cdot & \cdot \\ . & \end{array}$

$0.021)$

(0.027)

$\mathrm{N}$

25,251

25,251

25,251

$\begin{array}{cc}\cdot & 0.464 \\ \cdot & (0.023)\end{array}$

0.297

$\begin{array}{ccc}\cdot & 0.464 & 0.297 \\ . & (0.023) & (0.030)\end{array}$

Notes: The regressions also include an intercept. The ability measures have been standardized by year of draft. The father's abilities have been predicted by using the paternal uncle's abilities. The mother's abilities have been predicted by using the maternal uncle's abilities, and the relative sibling correlations in Table A3. Standard errors adjusted for clustering on the father are in parentheses. 
Table 7 Parental abilities and educational success, sons and daughters

\begin{tabular}{|c|c|c|c|c|c|c|}
\hline \multirow[b]{2}{*}{ Model: } & \multicolumn{3}{|c|}{ Sons } & \multicolumn{3}{|c|}{ Daughters } \\
\hline & $(1)$ & $(2)$ & (3) & $(1)$ & $(2)$ & (3) \\
\hline Dependent variable: & \multicolumn{6}{|c|}{ Academic achievement at age 16} \\
\hline \multirow[t]{2}{*}{$\begin{array}{l}\text { Independent variables: } \\
\text { Father's cognitive ability }\end{array}$} & 0.470 & & 0.330 & 0.446 & & 0.331 \\
\hline & $(0.026)$ & & $(0.028)$ & $(0.026)$ & & $(0.028)$ \\
\hline \multirow{2}{*}{ Father's non-cognitive ability } & 0.093 & & 0.061 & 0.138 & . & 0.071 \\
\hline & $(0.035)$ & & $(0.040)$ & $(0.035)$ & . & $(0.041)$ \\
\hline \multirow[t]{2}{*}{ Mother's cognitive ability } & $\cdot$ & 0.506 & 0.375 & . & 0.432 & 0.293 \\
\hline & & $(0.028)$ & $(0.030)$ & . & $(0.028)$ & $(0.030)$ \\
\hline \multirow[t]{2}{*}{ Mother's non-cognitive ability } & & 0.104 & 0.021 & . & 0.195 & 0.107 \\
\hline & & $(0.039)$ & (0.044) & . & $(0.039)$ & $(0.044)$ \\
\hline $\mathrm{N}$ & 15,214 & 15,214 & 15,214 & 14,484 & 14,484 & 14,484 \\
\hline Dependent variable: & \multicolumn{6}{|c|}{ GPA at age 16} \\
\hline \multirow[t]{2}{*}{$\begin{array}{l}\text { Independent variables: } \\
\text { Father's cognitive ability }\end{array}$} & 0.348 & & 0.236 & 0.333 & & 0.238 \\
\hline & $(0.016)$ & & $(0.017)$ & $(0.015)$ & & $(0.017)$ \\
\hline \multirow[t]{2}{*}{ Father's non-cognitive ability } & 0.242 & . & 0.173 & 0.252 & . & 0.163 \\
\hline & $(0.021)$ & . & $(0.024)$ & $(0.021)$ & . & $(0.025)$ \\
\hline \multirow[t]{2}{*}{ Mother's cognitive ability } & & 0.397 & 0.293 & . & 0.346 & 0.239 \\
\hline & & $(0.017)$ & $(0.018)$ & . & $(0.017)$ & $(0.018)$ \\
\hline \multirow[t]{2}{*}{ Mother's non-cognitive ability } & & 0.233 & 0.122 & . & 0.278 & 0.166 \\
\hline & & $(0.023)$ & $(0.027)$ & . & $(0.023)$ & $(0.027)$ \\
\hline $\mathrm{n}$ & 45,955 & 45,955 & 45,955 & 43,358 & 43,358 & 43,358 \\
\hline Dependent variable: & \multicolumn{6}{|c|}{ Years of schooling at ages $30-40$} \\
\hline \multirow[t]{2}{*}{$\begin{array}{l}\text { Independent variables: } \\
\text { Father's cognitive ability }\end{array}$} & 0.715 & & 0.482 & 0.504 & & 0.378 \\
\hline & $(0.081)$ & & $(0.088)$ & $(0.081)$ & . & $(0.092)$ \\
\hline \multirow[t]{2}{*}{ Father's non-cognitive ability } & 0.421 & . & 0.292 & 0.620 & . & 0.472 \\
\hline & $(0.106)$ & . & $(0.124)$ & $(0.114)$ & $\cdot$ & $(0.135)$ \\
\hline \multirow[t]{2}{*}{ Mother's cognitive ability } & & 0.906 & 0.712 & . & 0.511 & 0.347 \\
\hline & & $(0.086)$ & $(0.094)$ & . & $(0.094)$ & $(0.103)$ \\
\hline \multirow[t]{2}{*}{ Mother's non-cognitive ability } & & 0.345 & 0.147 & . & 0.572 & 0.295 \\
\hline & & $(0.116)$ & $(0.137)$ & . & $(0.118)$ & $(0.151)$ \\
\hline $\mathrm{n}$ & 13,231 & 13,847 & 13,847 & 12,380 & 12,380 & 12,380 \\
\hline
\end{tabular}

Notes: The regressions also include an intercept. The ability measures have been standardized. The father's abilities have been predicted by using the father's brother's abilities. The mother's abilities have been predicted by using the mother's brother's abilities, and the relative sibling correlations in Table A3. All models control for fixed effects for year of birth. Standard errors adjusted for clustering on the father are in parentheses. 
Table 8 Parental abilities and labor market success, sons and daughters

\begin{tabular}{|c|c|c|c|c|c|c|}
\hline \multirow[b]{2}{*}{ Model: } & \multicolumn{3}{|c|}{ Sons } & \multicolumn{3}{|c|}{ Daughters } \\
\hline & $(1)$ & $(2)$ & (3) & $(1)$ & $(2)$ & (3) \\
\hline Dependent variable: & \multicolumn{6}{|c|}{ Earnings at ages 30-40 (share of mean) } \\
\hline \multicolumn{7}{|l|}{ Independent variables: } \\
\hline \multirow[t]{2}{*}{ Father's cognitive ability } & 0.043 & . & 0.030 & 0.042 & . & 0.035 \\
\hline & $(0.018)$ & . & $(0.020)$ & $(0.017)$ & . & $(0.019)$ \\
\hline \multirow[t]{2}{*}{ Father's non-cognitive ability } & 0.135 & . & 0.104 & 0.118 & . & 0.100 \\
\hline & $(0.025)$ & . & $(0.029)$ & $(0.024)$ & . & $(0.028)$ \\
\hline \multirow[t]{2}{*}{ Mother's cognitive ability } & . & 0.043 & 0.024 & . & 0.035 & 0.015 \\
\hline & . & $(0.022)$ & $(0.024)$ & . & $(0.019)$ & $(0.021)$ \\
\hline \multirow[t]{2}{*}{ Mother's non-cognitive ability } & . & 0.133 & 0.084 & . & 0.096 & 0.045 \\
\hline & . & $(0.027)$ & $(0.030)$ & . & $(0.026)$ & $(0.031)$ \\
\hline $\mathrm{n}$ & 13,231 & 13,231 & 13,231 & 12,380 & 12,380 & 12,380 \\
\hline Dependent variable: & \multicolumn{6}{|c|}{$\mathrm{P}$ (Employed) at ages $30-40$} \\
\hline \multicolumn{7}{|l|}{ Independent variables: } \\
\hline \multirow{2}{*}{ Father's cognitive ability } & -0.013 & . & -0.019 & -0.003 & . & -0.004 \\
\hline & $(0.011)$ & . & $(0.013)$ & $(0.014)$ & . & $(0.015)$ \\
\hline \multirow[t]{2}{*}{ Father's non-cognitive ability } & 0.065 & . & 0.050 & 0.090 & . & 0.080 \\
\hline & $(0.016)$ & . & $(0.019)$ & $(0.018)$ & . & $(0.022)$ \\
\hline \multirow[t]{2}{*}{ Mother's cognitive ability } & . & 0.003 & 0.006 & . & -0.000 & -0.005 \\
\hline & . & $(0.013)$ & $(0.014)$ & . & $(0.015)$ & $(0.017)$ \\
\hline \multirow[t]{2}{*}{ Mother's non-cognitive ability } & . & 0.060 & 0.042 & . & 0.064 & 0.029 \\
\hline & . & $(0.017)$ & $(0.021)$ & . & $(0.021)$ & $(0.024)$ \\
\hline $\mathrm{n}$ & 13,231 & 13,231 & 13,231 & 12,380 & 12,380 & 12,380 \\
\hline Dependent variable: & \multicolumn{6}{|c|}{$\ln$ (Earnings) at ages $30-40$} \\
\hline \multicolumn{7}{|l|}{ Independent variables: } \\
\hline \multirow[t]{2}{*}{ Father's cognitive ability } & 0.053 & . & 0.046 & 0.062 & . & 0.051 \\
\hline & $(0.010)$ & . & $(0.010)$ & $(0.010)$ & . & $(0.010)$ \\
\hline \multirow[t]{2}{*}{ Father's non-cognitive ability } & 0.054 & . & 0.046 & 0.008 & . & 0.002 \\
\hline & $(0.013)$ & . & $(0.015)$ & $(0.013)$ & . & $(0.015)$ \\
\hline \multirow[t]{2}{*}{ Mother's cognitive ability } & . & 0.036 & 0.016 & . & 0.053 & 0.036 \\
\hline & . & $(0.011)$ & $(0.012)$ & . & $(0.010)$ & $(0.011)$ \\
\hline \multirow[t]{2}{*}{ Mother's non-cognitive ability } & . & 0.050 & 0.023 & . & 0.016 & 0.006 \\
\hline & . & $(0.014)$ & $(0.016)$ & . & $(0.014)$ & $(0.016)$ \\
\hline $\mathrm{n}$ & 10,333 & 10,333 & 10,333 & 8,104 & 8,104 & 8,104 \\
\hline
\end{tabular}

Notes: The regressions also include an intercept. The ability measures have been standardized. The father's abilities have been predicted by using the father's brother's abilities. The mother's abilities have been predicted by using the mother's brother's abilities, and the relative sibling correlations in Table A3. Earnings are measured in 2009. P(Employed) is the probability to earn more than the minimum wage on a yearly basis (SEK 175,000), and is estimated using a linear probability model. $\ln$ (earnings) is restricted to individuals who earn more than the minimum wage on a yearly basis. All models control for fixed effects for year of birth. Standard errors adjusted for clustering on the father are in parentheses. 